\title{
Umbilical trocar port site keloid management using a transposition flap after laparoscopic surgery
}

Hyo Jeong Kwon, Jung Hyeou Kim, Chae Rim Lee, Jangyoun Choi, Suk-Ho Moon, Young Joon Jun, Deuk Young $\mathrm{Oh}$

Department of Plastic and Reconstructive Surgery, College of Medicine, The Catholic University of Korea, Seoul, Korea
Background Keloids can occur anywhere in the human body. They are difficult to remove and can cause distress in patients. Although many options are available to treat keloids, no single method is considered the optimal treatment of choice. The authors encountered cases where an umbilical keloid developed at the trocar site after laparoscopic surgery and managed the keloid using a transposition flap.

Methods A total of 10 umbilical keloid patients treated from 2013 to 2020 were included in this study. All patients developed a keloid due to the placement of a laparoscopic trocar incision port, and their major complaints varied from an asymptomatic nodule to pruritus or pain. All excisions were performed under local anesthesia, and transposition flaps were planned afterward. The surrounding tissue was rearranged so that the shape of the umbilicus was deformed to the minimum extent possible. The keloid scars were examined both preoperatively and 6 months postoperatively using the Patient and Observer Scar Assessment Scale (POSAS).

Results All surgical wounds healed well without complications. The average time interval from laparoscopic surgery to keloid scar revision was 4.3 years. The mean postoperative follow-up period was 10.9 months, and no patient underwent reoperation. Four patients were treated with triamcinolone after surgery due to mild hypertrophy or pruritus. The POSAS observer scale showed significantly decreasing scores over time in all patients $(\mathrm{P}=0.002)$.

Conclusions Cosmetically unfavorable keloids that form in the umbilicus following laparoscopic surgery can be improved with a simple procedure using excision and transposition flaps.

Keywords Keloid / Umbilicus / Surgical flaps / Laparoscopy

\section{INTRODUCTION}

A keloid is a fibrous proliferative tumor caused by excessive scarring as granulation tissue overgrows. It appears as a hard, rubbery, or shiny fibrous nodule, with various colors and is accompanied by

Received: Jun 2, 2021 Revised: Jul 6, 2021 Accepted: Aug 20, 2021

Correspondence: Deuk Young Oh Department of Plastic and Reconstructive Surgery, College of Medicine, The Catholic University of Korea, 222 Banpodaero, Seocho-gu, Seoul 06591, Korea

Tel: +82-2-2258-6143, Fax: +82-2-594-7230, E-mail: ohdeuk1234@hanmail.net

Copyright $\odot 2021$ The Korean Society for Aesthetic Plastic Surgery.

This is an Open Access article distributed under the terms of the Creative Commons Attribution Non-Commercial License (https://creativecommons.org/licenses/by-nc/4.0/) which permits unrestricted non-commercial use, distribution, and reproduction in any medium, provided the original work is properly cited. www.e-aaps.org hyperpigmentation in many cases [1]. At first glance, keloids look similar to hypertrophic scars (HTS) and can cause similar symptoms, such as pruritus or pain. However, keloids can invade the surrounding healthy skin beyond the boundary of the original wound, extending the area of symptoms [2].

The predominant areas of keloid formation are the anterior chest, shoulder, arm, head, and neck, especially after piercings [3-5]. However, keloids can form in any part of the body where scarring occurs. Although keloids are not frequently found in the umbilicus, inserting a trocar port through the umbilicus during laparoscopic surgery can result in scars, including keloids.

The umbilicus, which is the only physiological scar present in the human body, is a remnant structure generated from the base of the umbilical cord [6,7]. Although it serves no biological function, the umbilicus is a key cosmetic feature as a landmark in the abdo- 
men. A missing or deformed umbilicus can cause psychological discomfort. Therefore, when performing scar revision in the umbilicus area, special attention is required regarding cosmetic appearance.

Several complications have been reported since the introduction of laparoscopy for general and gynecologic surgery. Because the occurrence of keloids at the trocar site is uncommon and considered to be a minor complication, few reports have addressed this issue despite the importance of the umbilicus [8]. In this report, the authors describe the management of patients who developed keloids after laparoscopic surgery.

\section{METHODS}

Ten patients who underwent laparoscopic surgery due to general surgical or gynecologic problems from 2013 to 2020 were included in this study. All patients had a history of trocar port insertion in the umbilicus area where localized nodules later developed. The keloid was diagnosed clinically by a single experienced plastic surgeon based on a history of laparoscopic surgery, the size and shape of the scar, growth pattern, and patient symptoms [9]. These symptoms included discomfort from palpable nodules caused by protruding scars, an itching sensation, and pain. The interval between laparoscopic surgery and keloid surgery was investigated for each patient, and the length and width of the keloid were measured (Table 1).

The shape of the keloid was classified into one of three types: round, ovoid, or irregular. An irregular shape was considered to be present when the shape of the nodule itself was not uniform or when stable and/or linear scars were mixed around a protruding keloid. The follow-up period after keloid surgery was recorded, and recurrence was investigated. Recurrence was defined as regeneration of the nodule after surgery. None of the patients had a previous history of other treatments for keloids.

In addition, the Patient and Observer Scar Assessment Scale
(POSAS) score was calculated based on five categories (vascularity, pigmentation, thickness, relief, and pliability) as an objective evaluation of each patient's scar. The preoperative and 6-month postoperative values were calculated, and the significance of changes was evaluated by determining the P-value. Each item was evaluated on a scale from 1 to 10 points. A score of 1 indicated an appearance close to that of the normal skin, while a score of 10 represented the worst scar imaginable [10]. The Wilcoxon signed-rank test was used to compare the values before surgery and 6 months after surgery. All statistical analyses were carried out in GraphPad Prism version 9.0.1 (GraphPad Software Inc., La Jolla, CA, USA).

During the preoperative consultation, the authors explained to the patients that the keloid overlying the umbilicus would be removed. The possibility of umbilicus reconstruction would be available later if desired. An incision line was chosen and marked after a local injection. It was designed to include the entire keloid nodule, but not to remove linear scars if there was an irregular shape or an

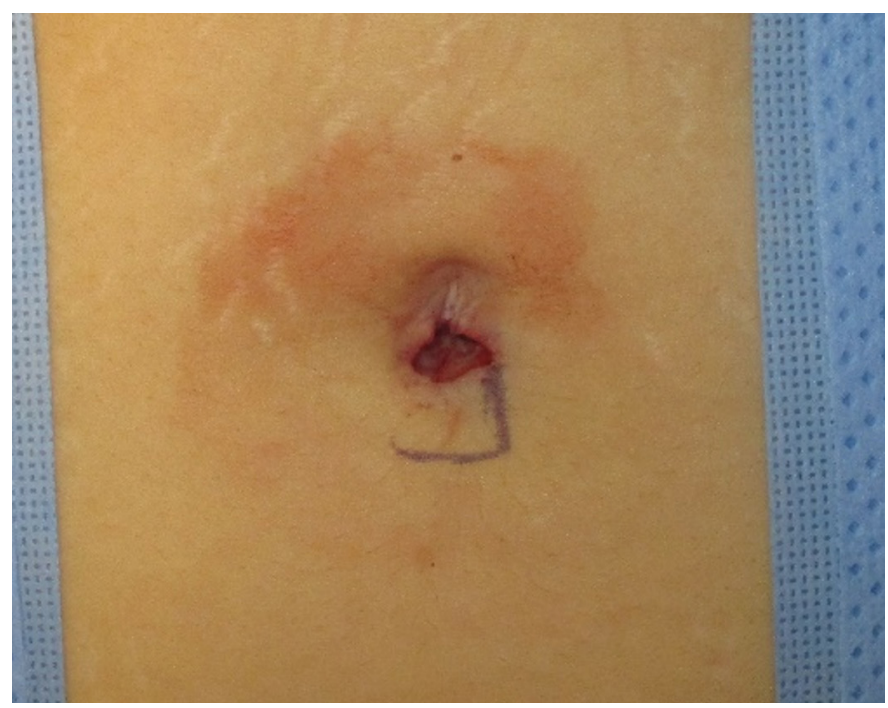

Fig. 1. Design of a basic transposition flap.

Table 1. Demographic and clinical characteristics of 10 patients with trocar site keloids at the umbilicus

\begin{tabular}{|c|c|c|c|c|c|c|c|}
\hline Patient No. & Age (yr) & Sex & Complaint & Previous surgery & Interval (yr) & Size $(\mathrm{cm})$ & Shape \\
\hline 1 & 58 & Female & Discharge, pruritus & Laparoscopic hysterectomy & 20 & $2 \times 3$ & Irregular \\
\hline 2 & 38 & Female & Asymptomatic nodule & Laparoscopic subtotal gastrectomy & 1 & $1.5 \times 1.5$ & Ovoid \\
\hline 3 & 44 & Female & Pain, pruritus & Laparoscopic hysterectomy & 4 & $1.5 \times 2.5$ & Ovoid \\
\hline 4 & 63 & Female & Pain & Laparoscopic right adnexectomy & 1 & $1 \times 1$ & Round \\
\hline 5 & 57 & Female & Pain, pruritus & Laparoscopic hysterectomy & 3.5 & $2.5 \times 2$ & Irregular \\
\hline 6 & 41 & Female & Pain, pruritus & Laparoscopic right adnexectomy & 5 & $2 \times 2$ & Irregular \\
\hline 7 & 37 & Female & Asymptomatic nodule & Laparoscopic left ovary cystectomy & 1.5 & $2 \times 1$ & Irregular \\
\hline 8 & 41 & Female & Pruritus & Laparoscopic myomectomy & 3 & $1 \times 1$ & Round \\
\hline 9 & 55 & Female & Asymptomatic nodule & Laparoscopic hysterectomy & 2 & $1 \times 1$ & Round \\
\hline 10 & 48 & Female & Pain, pruritus & Laparoscopic right ovary cystectomy & 2 & $1 \times 1.5$ & Round \\
\hline
\end{tabular}


area anticipated to be severely disfigured when removed. A skin incision was performed along the preoperative marking, and then the keloid overlying the umbilicus was excised. Next, a transposition flap was designed to cover the subsequent defect (Fig. 1). It is not difficult to transpose soft tissue near the defect because the soft tissue of the abdomen stretches well and is not scarce. The flap was designed as a rhomboid transposition flap, and the design was adjusted depending on the shape of the defect. The surrounding tissues were incised and rearranged carefully, considering the shape, size, and location of the scar. The final scar was vertical and placed as close as possible to the middle of the original umbilicus. The subcutaneous layer was then closed with 4-0 Vicryl sutures, and the skin layer was closed with 5-0 nylon sutures. Stitches were removed about 2 weeks after surgery.

Table 2. Surgical outcomes

\begin{tabular}{lc}
\hline Variable & Value \\
\hline Age (yr), average \pm SD & $48.2 \pm 9.4$ \\
Interval until keloid revision (yr), average \pm SD & $4.3 \pm 5.7$ \\
Follow-up period (mo), mean \pm SD & $10.9 \pm 11.0$ \\
Reoperation, No. (\%) & 0 \\
Yes & $10(100)$ \\
No & $10(100)$ \\
Postoperative adjunct therapy, No (\%) & $4(40)$ \\
Silicone gel & 0 \\
Triamcinolone injection & \\
Radiation therapy &
\end{tabular}

\section{RESULTS}

All 10 patients were female, and their average age was 48.2 years. The shape of the keloid scar was round in $40 \%$ of patients, ovoid in $20 \%$, and irregular in $40 \%$. All operations were performed under local anesthesia. The average interval from laparoscopic surgery to keloid scar revision was 4.3 years. The mean follow-up period was 10.9 months, and no patient required reoperation due to the recurrence of keloid nodules during this period. All patients used silicone gel on the incision site after surgery. Four patients developed postoperative pruritus, which was managed by a triamcinolone injection (Table 2).

Patients were evaluated for each item using the POSAS observer scale, and the average was calculated for each item. The mean vascularity score was 7 points before surgery and 2.3 points after surgery, while the mean pigmentation score was 6 points preoperatively and 2.5 points postoperatively. The average thickness score was 7.1 points before surgery and 1.4 points after surgery, while the mean relief score was 6.7 points before surgery and 1.7 points after surgery. The average score for pliability decreased from 6.4 points to 2.1 points (Table 3). For all items, the P-value was 0.002 (Fig. 2).

Regarding the shape of the umbilicus after surgery, in all patients, the original umbilicus was located in the middle of the abdomen even after the transposition flap was performed. Therefore, there was no disfiguration. In addition, there were no cases in which the natural depression disappeared and appeared flat, as the stalk was not entirely sacrificed during surgery.

Table 3. Comparison of Patient and Observer Scar Assessment Scale (POSAS) scores before and after surgery

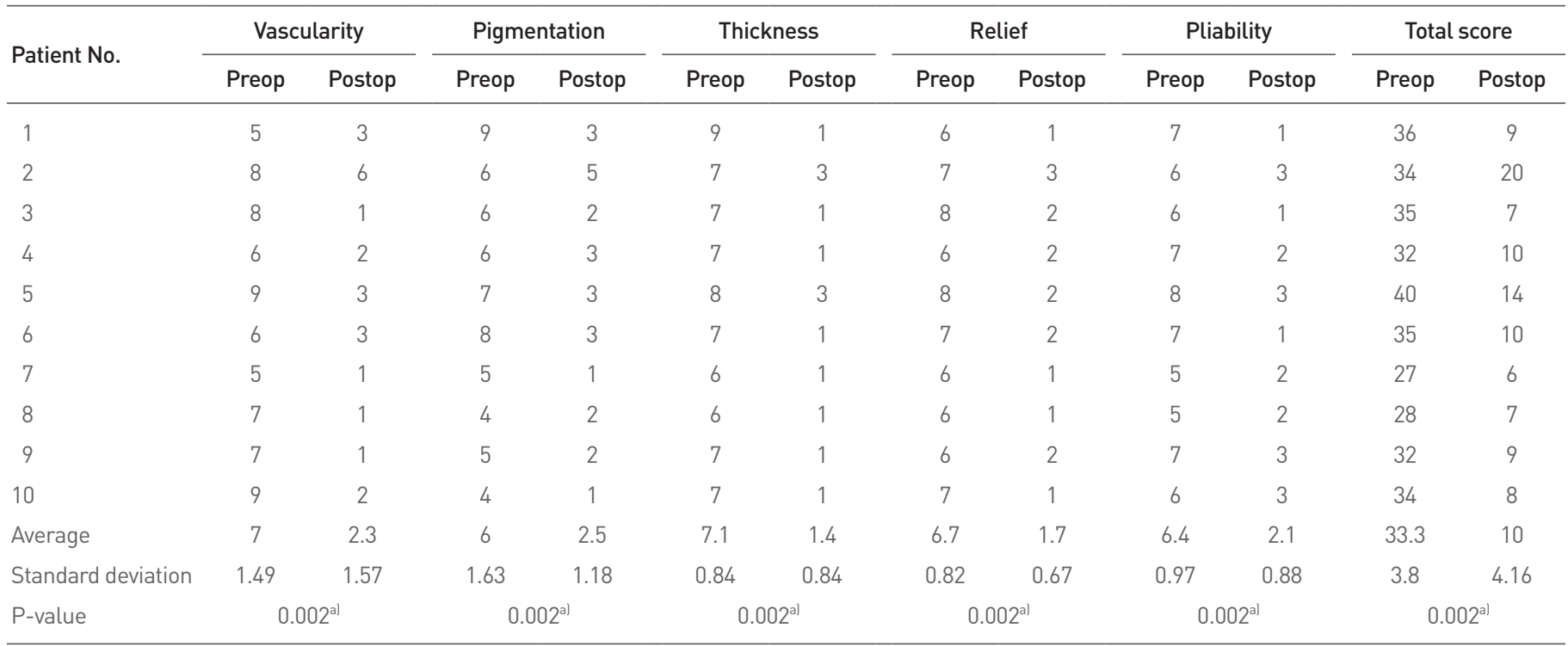

Preop, preoperative; Postop, postoperative.

${ }^{a)} \mathrm{P}<0.01$. 


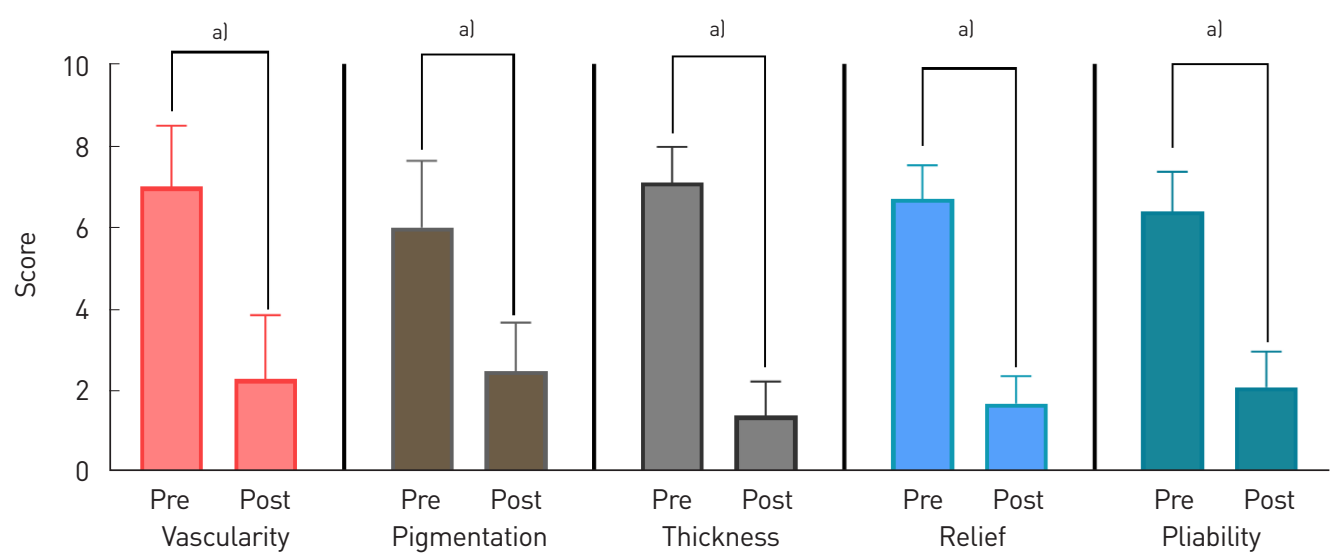

Fig. 2. The Patient and Observer Scar Assessment Scale (POSAS) observer scale. The mean vascularity score was 7 points before surgery and 2.3 points after surgery, and the mean pigmentation score was 6 points preoperatively and 2.5 points postoperatively. The average thickness score was 7.1 points before surgery and 1.4 points after surgery. The mean relief score was 6.7 points preoperatively and 1.7 points postoperatively. The average value of pliability score decreased from 6.4 points to 2.1 points. ${ }^{\text {a) }}$ For all items, the $\mathrm{P}$-value was $0.002(\mathrm{P}<0.01)$.

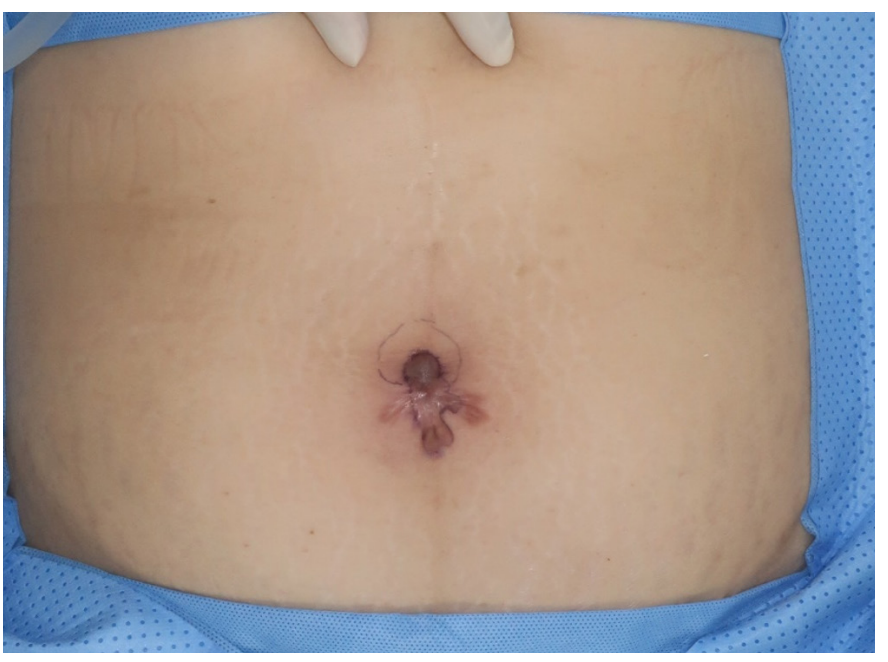

Fig. 3. Preoperative clinical picture. An irregularly shaped nodule around $2 \times 3 \mathrm{~cm}$ in diameter was identified.

\section{Cases}

Case 1

Patient 1 visited our clinic with an umbilical keloid. She had a history of laparoscopic total hysterectomy due to endometriosis that had been performed at a gynecologic clinic 20 years ago. An irregularly shaped nodule, measuring approximately $2 \times 3 \mathrm{~cm}$ in diameter, was identified, and intermittent discharge and pruritus were present (Fig. 3). Therefore, keloid excision was performed, and a transposition flap was created (Fig. 4). No recurrence was found 6 months after surgery. The patient reported that her symptoms had improved (Fig. 5).

\section{Case 2}

Patient 2 visited our clinic with an umbilical keloid. She had a history of laparoscopic right adnexectomy 5 years ago. An irregularly shaped, painful nodule, measuring approximately $2 \times 2 \mathrm{~cm}$ in diameter, was identified preoperatively (Fig. 6). Therefore, excision
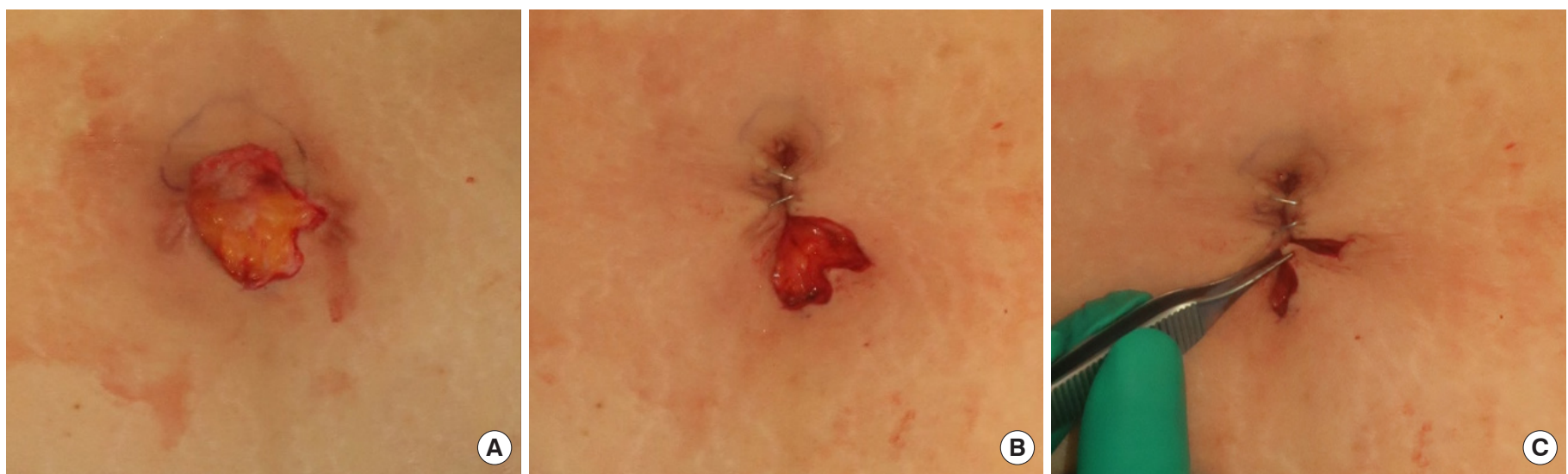

Fig. 4. A defect occurred after excision of the keloid nodule (A). A transposition flap is applied to create a vertically oriented scar (B, C). 


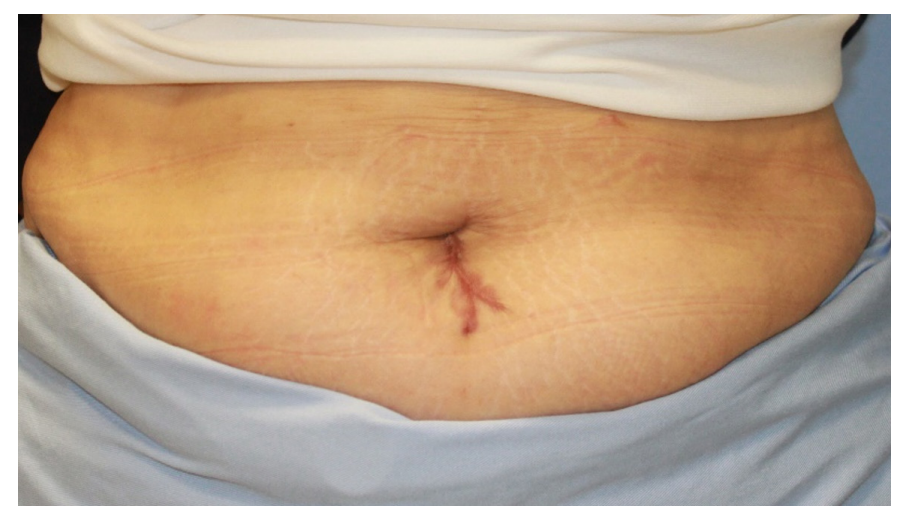

Fig. 5. A clinical picture of patient 1 at 3 months after surgery.

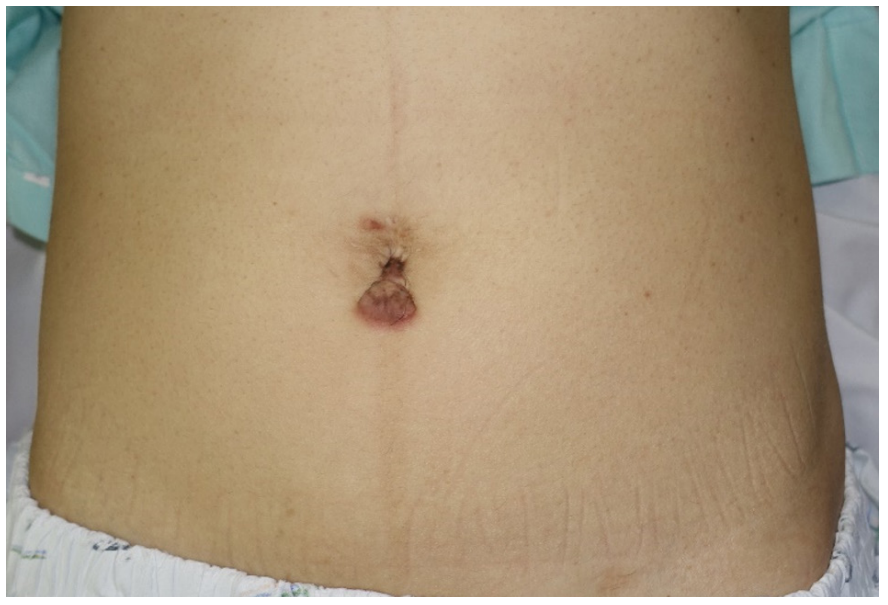

Fig. 6. Preoperative clinical picture of patient 7. An irregularly shaped nodule around $2 \times 1 \mathrm{~cm}$ in diameter was identified.

was performed, and a transposition flap was created (Fig. 7). The site was stable, with no recurrence, 3 years after surgery (Fig. 8).

\section{DISCUSSION}

A keloid is a result of excessive scar tissue formation beyond the boundary of the initial wound during the healing process after a skin injury. A keloid does not disappear spontaneously. Keloid tissue is characterized by an excessive accumulation of extracellular matrix, especially collagen, in the dermis and subcutaneous layers $[11,12]$. Keloids occur as hard nodules and can cause patients significant psychological distress due to their appearance; uncomfortable physical symptoms, such as pruritus or pain, can also be present. Keloids are often confused with HTS, but these conditions are significantly different, as HTS does not expand beyond the existing wound boundary, often disappears spontaneously, and does not recur after excision. In addition, HTS occurs within a few weeks after skin injury, whereas keloids exhibit a more delayed onset $[2$,
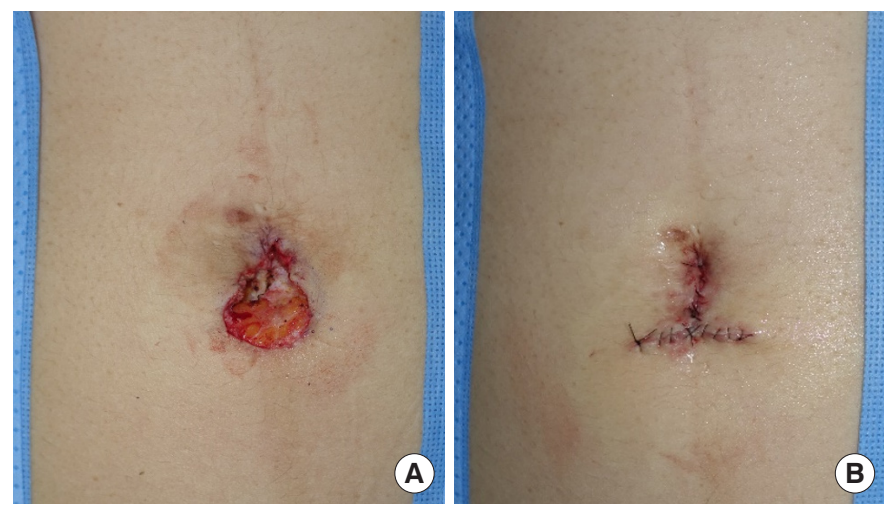

Fig. 7. A defect occurred after excision of the keloid nodule (A). The appearance of the inverted T-shaped scar after creating a transposition flap (B).

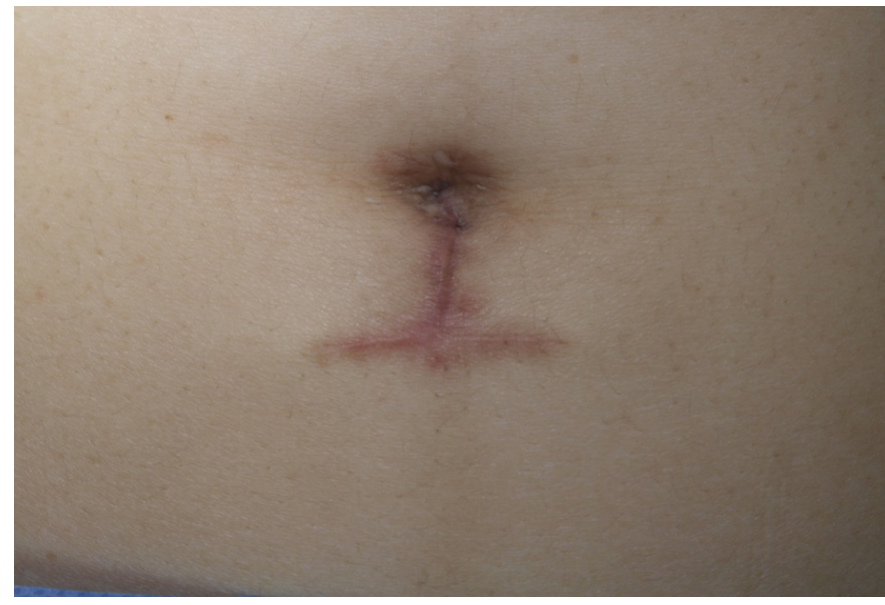

Fig. 8. A clinical picture of patient 7 taken 3 years after surgery.

13,14].

Keloids occur mainly in the anterior chest, shoulder, arm, head, and neck areas. Keloids are also often noted on the ears after piercing [3-5]. However, they also can occur in any part of the human body where scarring is possible. The umbilicus is not a well-known site for keloids, but umbilical keloids have been reported. The umbilicus, which is a remnant structure generated from the umbilical cord, is the only physiological scar present in the human body. It has no function postpartum, but acts as a very important cosmetic feature of the abdomen [6,7]. For this reason, scar revision of the umbilicus is important psychologically, and various methods for umbilicoplasty have been introduced in the literature [15-19]. Plastic surgeons typically try to create an attractive umbilicus in a vertically oriented shape with superior hooding of a suitable size [20].

The differential diagnosis of a nodule in the umbilicus after surgery using a trocar during laparoscopy should include some conditions other than keloids [21]. First, umbilical endometriosis has a very similar clinical presentation to that of umbilical keloids, mak- 
ing the diagnosis challenging. The best way to differentiate these two entities is based on symptoms. Umbilical endometriosis is characterized by cyclic pain, swelling, and bloody discharge associated with the menstrual period [22]. In addition, it is necessary to differentiate keloids from Sister Mary Joseph nodules, which represent metastasis of visceral carcinoma, through imaging studies such as computed tomography [23].

Several hypotheses have been proposed regarding the etiopathology of keloids; however, it is not clear which factors play a major role in keloid development $[1,12]$. Therefore, the treatment of choice has not been established, although several options are recommended. Historically, surgical excision has been considered the mainstay of keloid treatment [24]. Keloids tend to recur even after total surgical resection. Therefore, complete treatment is difficult with surgery alone, and surgeons are beginning to favor multimodal treatment methods. The most common additional treatment is corticosteroid injection into the lesion [5]. Corticosteroids have anti-inflammatory properties and inhibit the production of fibroblasts by reducing collagen and synthesizing glycosaminoglycans. In addition, superficial radiation therapy, autologous plateletrich plasma, bleomycin, or verapamil can be applied as adjuvant therapies [25].

In this study, the authors performed surgical excision of umbilical keloids. Special attention was taken to create an umbilicus with the most natural possible appearance. The surrounding soft tissue was used to form a vertically oriented or T-shaped scar. The POSAS observer scale was used to rate scars both preoperatively and 6 months postoperatively. The end results showed significant improvements in all indices, indicating that the scar was camouflaged after the creation of a transposition flap. The patients were satisfied with the results and did not request neoumbilicoplasty. There was no case of keloid nodule recurrence. Four patients complained of pruritus, but their symptoms improved after triamcinolone injection.

The limitations of this report are its small sample size and short average follow-up period. In addition, the retrospective study design meant that it was not possible to report subjective POSAS scores. Nevertheless, the objective POSAS scores showed improvement. Therefore, even if a keloid occurs in the umbilicus area after laparoscopic surgery, satisfactory cosmetic outcomes can be obtained through coverage with a transposition flap.

In conclusion, cosmetically unfavorable keloids that occur in the umbilicus area after laparoscopic surgery can be managed through a simple procedure using excision and a transposition flap.

\section{NOTES}

\section{Conflict of interest}

No potential conflict of interest relevant to this article was reported.

\section{Ethical approval}

The study was approved by the Institutional Review Board of the Catholic Medical Center Office of Human Research Protection Program (IRB No. KC21RASI0353) and performed in accordance with the principles of the Declaration of Helsinki.

\section{Patient consent}

The patients provided written informed consent for the publication and the use of their images.

\section{ORCID}

Hyo Jeong Kwon Jung Hyeou Kim Chae Rim Lee Jangyoun Choi Suk-Ho Moon Young Joon Jun Deuk Young Oh https://orcid.org/0000-0002-5778-5692 https://orcid.org/0000-0002-2662-3631 https://orcid.org/0000-0001-6537-5696 https://orcid.org/0000-0002-5165-8414 https://orcid.org/0000-0003-1866-2910 https://orcid.org/0000-0001-6537-2460 https://orcid.org/0000-0003-3499-1554

\section{REFERENCES}

1. Al-Attar A, Mess S, Thomassen JM, et al. Keloid pathogenesis and treatment. Plast Reconstr Surg 2006;117:286-300.

2. Limandjaja GC, Niessen FB, Scheper RJ, et al. Hypertrophic scars and keloids: overview of the evidence and practical guide for differentiating between these abnormal scars. Exp Dermatol 2021;30:146-61.

3. Robles DT, Berg D. Abnormal wound healing: keloids. Clin Dermatol 2007;25:26-32.

4. Du G, Zhu J. Ear keloid and clinical research progress. Lin Chung Er Bi Yan Hou Tou Jing Wai Ke Za Zhi 2014;29:770-2.

5. Jones ME, McLane J, Adenegan R, et al. Advancing keloid treatment: a novel multimodal approach to ear keloids. Dermatol Surg 2017;43: 1164-9.

6. Rodriguez-Feliz JR, Makhijani S, Przybyla A, et al. Intraoperative assessment of the umbilicopubic distance: a reliable anatomic landmark for transposition of the umbilicus. Aesthetic Plast Surg 2012;36:8-17.

7. Southwell-Keely JP, Berry MG. Umbilical reconstruction: a review of techniques. J Plast Reconstr Aesthet Surg 2011;64:803-8.

8. Sirito R, Puppo A, Centurioni MG, et al. Incisional hernia on the 5-mm trocar port site and subsequent wall endometriosis on the same site: a case report. Am J Obstet Gynecol 2005;193(3 Pt 1):878-80.

9. Ogawa R, Akita S, Akaishi S, et al. Diagnosis and treatment of keloids and hypertrophic scars: Japan Scar Workshop Consensus document 2018. Burns Trauma 2019;7:39.

10. van der Wal MB, Tuinebreijer WE, Lundgren-Nilsson A, et al. Differential item functioning in the Observer Scale of the POSAS for different scar types. Qual Life Res 2014;23:2037-45.

11. Andrews JP, Marttala J, Macarak E, et al. Keloids: the paradigm of skin fibrosis: pathomechanisms and treatment. Matrix Biol 2016;51:37-46.

12. Bran GM, Goessler UR, Hormann K, et al. Keloids: current concepts 
of pathogenesis (review). Int J Mol Med 2009;24:283-93.

13. Burd A, Huang L. Hypertrophic response and keloid diathesis: two very different forms of scar. Plast Reconstr Surg 2005;116:150e-157e.

14. Mostinckx S, Vanhooteghem O, Richert B, et al. Keloid and hypertrophic scar. Ann Dermatol Venereol 2005;132:384-7.

15. Gardani M, Palli D, Simonacci F, et al. Umbilical reconstruction: different techniques, a single aim. Acta Biomed 2019;90:504-9.

16. Wirtz EC, Williams BM, Nakayama DK. Keyhole umbilicoplasty to reconstruct the umbilicus after repair of probscoid umbilical hernia. Am Surg 2020 Dec 28 [Epub]. https://doi.org/10.1177/0003134820982869.

17. Bawazir OA. A new umbilicoplasty technique for the management of large umbilical hernia in children. Hernia 2019;23:1261-6.

18. Bruekers SE, van der Lei B, Tan TL, et al. "Scarless" umbilicoplasty: a new umbilicoplasty technique and a review of the English language literature. Ann Plast Surg 2009;63:15-20.

19. Kim DC, Shin CH, Yu SH, et al. Keyhole vertical mini-abdominoplas- ty for correction of lower abdominal striae. Arch Aesthetic Plast Surg 2020;26:173-7.

20. Craig SB, Faller MS, Puckett CL. In search of the ideal female umbilicus. Plast Reconstr Surg 2000;105:389-92.

21. Jaime TJ, Jaime TJ, Ormiga P, et al. Umbilical endometriosis: report of a case and its dermoscopic features. An Bras Dermatol 2013;88:121-4.

22. Loh SH, Lew BL, Sim WY. Primary cutaneous endometriosis of umbilicus. Ann Dermatol 2017;29:621-5.

23. Yamashita S, Sakon M, Hiura Y, et al. A case of metastases of umbilicus (Sister Mary Joseph's nodule). Gan To Kagaku Ryoho 2008;35:2112-4.

24. Seo BF, Ko HS, Kwon H, et al. V-Y advancement flap: aesthetic reconstruction for auriculotemporal keloid excision. Arch Aesthetic Plast Surg 2017;23:164-7.

25. Xu J, Yang E, Yu NZ, et al. Radiation therapy in keloids treatment: history, strategy, effectiveness, and complication. Chin Med J (Engl) 2017; 130:1715-21. 